\title{
MUNICIPAL COASTAL GOVERNANCE TOWARDS RURAL COMMUNITY RESILIENCE DEVELOPMENT: SCENARIOS AND TOOLS
}

\author{
ĒRIKA LAGZDIN̦A, IVARS KUDREN̦ICKIS, RAIMONDS ERNŠTEINS \& ANITA LONTONE \\ University of Latvia, Latvia
}

\begin{abstract}
Coastal systems are complex resources systems based on interconnected elements of nature, economic, social, cultural, and, importantly, governance resources. Governance of the coastal territories as socioecological systems shall be integrated, holistic, multi-faceted and multi-level process oriented. Studies in Latvia identify insufficient knowledge/skills and even understanding/interest of decision-makers and administrations to deal with integrated coastal management (ICM) at all levels, and, particularly, with integration of the coastal problematic into mandatory development planning processes. Governance capacity is especially critical in rural coastal municipalities often with also long coastlines, making above $80 \%$ altogether of the total national coast length; a subsequent need to find appropriate rural coastal governance models is evident. Within EU BONUS BaltCoast project, including most of Baltic Sea region countries, the System Approach Framework is tested in the national pilot territories, and, in Latvia, the Salacgriva municipality pilot as for rural coastal governance development case. Research activities demonstrate transition from individual isolated studies to integrated comprehensive multidisciplinary coastal research. Within this study the effective coastal governance scenarios approaches, tools, and development opportunities were analysed studying main generic governance development approaches. Analysis shows that none of top-down and bottom-up governance improvement scenarios alone can ensure effective rural coastal governance, and, obviously, collaborative governance scenarios (CGSs) shall be designed and implemented to really improve ICM, but the selection of adequate instruments for this could be seen as the issue. Research-and-development work addresses the following locally based coastal governance instruments which have to be complementary included in the CGS, namely - coastal science and governance report; municipal coastal collaborative monitoring programme, involving mandatory citizen science component; development of coastal indicators systems; and thematic coastal spatial plan, as all being local innovations for Latvia. These tools shall contain clearly identifiable science-based quantified numerical information, shall be integrative in their nature and succession and complementarity with other instruments.

Keywords: citizen science, coastal integrated management, collaborative governance, flood risk, indicator system, socio-ecological system, stake-holders, system approach framework, science-policy interface.
\end{abstract}

\section{INTRODUCTION}

It has been recognized in numerous policy documents shaping development of the Baltic Sea Region that integrated coastal management (ICM) is one of the most important challenges and ways to reach sustainable development of the Baltic Sea region. At the same time, a number of research papers identify that decision-makers and administrations at all governance levels have insufficient knowledge and skills to cope with the ICM and integration of the coastal problematic into development planning processes.

The Latvian coast stretches along the Baltic Sea and the Gulf of Riga for $496 \mathrm{~km}$, and it provides a living space for more than 990 thousand people out of whom $90 \%$ live in four large cities, but the rest - in medium- and small-sized (rural) municipalities. They belong to two planning regions - Vidzeme and Kurzeme. In general, Latvian rural coastal municipalities are characterised by low density population and disperse settlements (villages, 
small towns), considerably high level of nature protection status due to presence of valuable coastal biotopes and geological structures, and unfortunately - limited municipal capacity (administrative, financial, and knowledge wise etc.) to implement ICM. It is important to mention that during summer season the population of the coastal municipalities increases two to four-fold due to tourists, visitors and summer (short-time) residents. It creates pressure on the coastal resources causing risks of coastal degradation [1].

Inability of municipalities to cope with coastal governance challenge in effective way brought researchers of the BONUS BaltCoast project to the evident priority task - to find such coastal territory and coastal resources governance models, which are adequate and wellfunctioning in the case of rural local municipalities which have specific circumstances (particularly, long stretching shorelines; limited human, administrative, financial capacities, tools and instruments), and effective to maintain sustainably such complex socio-ecological systems (SES) as the coastal territories are.

The case study territory analysed in this article - Salacgriva municipality is one of 17 Latvian coastal municipalities. As a result of the last administrative territorial reform completed in 2009 , the municipality unites three former coastal rural municipalities. Its total area now is $638 \mathrm{~km}^{2}$ and population size is 7825 inhabitants (01.01.2016 Census data), out of whom $36 \%$ people live in the Salacgriva town, 9.5\% - in Ainazi town, and the rest are scattered in numerous smaller settlements (villages). Population density in the municipality is 13.9 residents per $\mathrm{km}^{2}$ that is 2.5 times below the average level in the country. But the population density in its rural areas (excluding two towns) is even less -7 inhabitants per $\mathrm{km}^{2}$. Other important characteristics of the Salacgriva municipality are: location in the North of the country, $55 \mathrm{~km}$ long and 5 to $15 \mathrm{~km}$ wide coastal zone (that is approximately $10 \%$ of the total Latvian coastline), and it is bordering with Estonia, besides distance from a capital Riga is relatively short, which provides for good accessibility by contemporary road traffic means. Salacgriva belongs to the active local governments, as they are piloting new governance approaches in their daily work. This creates a basis for detailed research of the governance models of the coastal municipalities that is discussed in this article.

\section{METHODOLOGY}

It is generally known that coastal territories encompass significant environmental, economic, social, cultural and recreational value. Importantly, coast as a socio-ecological system (SES) is based on interconnected elements of complex resources system consisting of natural, cultural, socio-economic and governance resources. They are essential elements of the coastal zone management that shall be integrated into one holistic system. Thus, governance of the coast as a system requests wide knowledge, information and skills, as it shall be multifaceted and multi-level process, including national, local and societal levels.

The basic overarching methodology applied in this research is based on System Approach Framework (SAF). The SAF is an issue oriented investigation and methodology that applies a holistic perspective [2]-[4]. It investigates and quantifies the functions of systems in order to simulate specific questions concerning their functions or policies. Thus, the SAF comprises the process (steps) from issue identification through system analyses to policy implementation. However, several complementary, targeted approaches/tools have been used to study specific elements of the coastal system and municipality in general. The basis of this article are findings from the BaltCoast project - A Systems Approach Framework for Coastal Research and Management in the Baltic. The overall task of the project is to apply the SAF for analysis and solving of essential coastal issues that have to be identified and addressed 
by involving stake-holders. This method has been developed and assessed in other cases around the Baltic Sea [5], [6].

The Latvian case of the Salacgriva municipality has been chosen to test and adapt the SAF for the coastal governance development situation. Thus, the SAF objective in the Latvian case is to provide multidisciplinary/transdisciplinary advice to the local policy-makers and managers concerning coastal municipal governance problems in the coastal territory by defining most efficient governance scenarios including governing approaches, tools, and governance development opportunities.

The key element of the SAF is stake-holder's involvement in the whole process. Involvement of stake-holders at the same time is a project requirement, and also methodological challenge due to the complexity of the addressed governance issue. Stakeholder participation is maintained through multi-step iteration process within the issue identification phase and solutions discussions. It has started with comprehensive stakeholder studies and institutional mapping, using targeted in-depth interviews, complemented by surveys during field studies and interactive stake-holder seminars. Due to the complexity of analysed coastal SES, sometimes stake-holders involvement became problematic, so it was replaced by the discussions with the Reference group (experts and municipal specialists).

The Latvian approach in the BaltCoast project is backed up by previous studies in the Salacgriva and other Latvian coastal municipalities, as the University of Latvia has been carrying out disciplinary and multidisciplinary coastal research for many decades. These studies provide broad picture of the coastal processes and resources, particularly in fields of geography, geology and biology sciences, and lately - as regards governance studies. It has to be acknowledged that experience of the coastal social and economic processes research in Latvia is considerably shorter, though it is growing rapidly thanks to several European level research projects implemented during last years.

In general, knowledge of the coastal SES including its four sustainability dimensions was built using various coastal contexts and sources of information, as well as utilizing and adapting for specific needs those tools that are characteristic to the SAF, particularly stakeholder involvement methods. Namely, (i) analysis of official statistics and data bases and document studies, combined with expert consultations (the SAF Reference group concept); (ii) nature and social sciences based on-site empirical studies (including such study areas as coastal geological processes, environmental management, local initiatives, governance practice (specifically exploring climate change (floods) case), institutional mapping etc.). All those methods were utilized in their complexity, complementarity within the case study research as general concept. They all together ultimately aimed at comprehensive assessment of the coastal governance practice and investigation of instruments use for the ICM (including costal communication instruments) [7], [8].

Multidisciplinary studies completed within the BaltCoast project have extended scope of knowledge on the coast as a socio-ecological system (SES). To conceptualize and design the system model representing its bottom-triple line sustainability dimensions and complementary - governance dimension, SAF as the system thinking language tool was applied. It has resulted in definition of the main system elements and interlinkages among system elements and ultimately developed large-scale complex model that helped to investigate coastal resources' use scenarios and their sustainability, as well as socioenvironmental impacts. Use of the coastal resources for tourism development is the one of the first sub-models which was tested investigating deeper processes from both local development perspective and stakeholders view-point. 


\section{RESULTS AND DISCUSSION}

\subsection{Climate change governance case study}

Earlier studies performed by the University of Latvia researchers and students in the Latvian municipalities show that there is insufficient interest and understanding from municipal administration as regards climate change related issues [9], [10]. Studies reveal generally missing municipal climate change governance (MCCG) process, structures and products - it is neither inter-sectorial target oriented, nor disciplinary one or cross-sectorial integrated one, both being necessary complementary and supported by whole range of implementation instruments in order to manage successful collaborative MCCG. Moreover, climate change policy at the local level still is often seen as a tool to attract financial resources and use international co-operation for climate related projects. The steps performed within the complex study of the climate change governance include:

1. Analysis of on MCCG development with emphasis on climate change adaptation strategy case in the Salacgriva municipality;

2. Sociological survey of the Salacgriva households/inhabitants;

3. Nation-wide municipal planners/ specialists survey (web-based);

4. Municipal indicators set for adaptation to climate change;

5. General recommendations for development of the MCCG.

Research methodology in this particular study was based on the complementary set of qualitative and quantitative methods, namely:

1. Integrated case study research in the Salacgriva coastal municipality, including analysis of planning and legislative documents, reports etc., interviews (in-depth interviews on MCCG at local level, e.g. implementation instruments, integration and stakeholder group co-operation), questionnaires (with inhabitants and stakeholders.)

2. Sociological survey with Salacgriva inhabitants. As a target audience were chosen households (private home owners) located nearby coastal sea and the Salaca river delta of Salacgriva town, especially from town areas being split into eventual flood zones according to the different likelihood of the risk of flooding there [10]. Number of questionnaires spread was 200, received answers - from 130 households (respondents).

3. Nation-wide municipal specialists' web based survey and interviews with national agencies' experts. Information e-mails were sent to 110 local municipalities (except large cities) and 47 answers were received.

Accordingly, to the general research approach of the University of Latvia, three sustainable development components (environment, social and economic dimensions) were studied based on the sectorial analysis. Besides, a complementary forth governance dimension was studied as it is considered to be a crucial for cross- and inter-disciplinary municipal issues investigation (climate and coastal issues are just some of them). Governance dimension elements are: local administration structure and content; interaction process for decision making preparation and taking, within particular administrative environment, and related municipal products/ services [10].

Outcomes of the research are related to development of collaborative governance model [9]. The model is based on concept that any sector or cross-sector governance shall be implemented through integrative collaboration of all governance cycle components. This model consists of five complementary components: internal and external governance 
stakeholder groups mutual collaborative development; vertical and horizontal integrative thematic collaborative development; governance tools collaborative development; governance assessment (indicator based top-down and bottom-up assessment) collaborative development; and governance communication collaborative development.

In general, Salacgriva municipality could be recognized as MCCG development model territory as it has adopted Green Municipality Declaration (2010), Salacgriva Municipality Climate Change Adaptation Strategy (2011), and implemented a range of climate/energy projects, and now has been working on MCCG integrated planning approaches.

When performing a sociological survey on flood risk in the Salacgriva town households, particular attention was paid to the governance environment, especially to the communication elements both in internal administrative and external stakeholders oriented climate change communication. Results characterize the governance problem - insufficient use of communication tools. Majority of interviewed inhabitants recognize climate change impacts in their surrounding territory (spring river flooding, heavy rain falls, storm surge and sea level raise), though inhabitants have not heard information on flood risks $-50 \%$, answers but $29 \%$ have heard something on this topic in the national TV or radio, but only $21 \%$ have ever received locally related information. Almost none of respondents have ever participated in any training activities on flood risks, except 11 persons which participated as employees of the municipal and port administration. Only $10 \%$ of inhabitants surveyed have ever took part in any local public hearing/participation activity, even $32 \%$ have heard of such possibility, but $58 \%$ never heard of citizen participation options.

Nationwide municipal planners survey reveals discrepancy between respondents' attitudes towards the role of municipalities in combating climate change and how the local municipality understands the need of MCCG and there is no consensus among respondents if the municipality should develop its own climate change governance document as there is the equal number of yes/no answers. Replies show that collaboration of local municipalities with different target groups is inactive. As limiting factors are mentioned the financial resources and the lack of interest/motivation to collaborate on the side of the relevant target groups. At the same time, the importance of the target group information/education is evaluated by approx. in $40 \%$ of answers. It was identified that Latvia municipalities do have enough instruments to start proactive governance. Empiric research reveals important fact of ineffective communication between municipality and stakeholders. In general, it is important for municipality to understand the necessity for development of MCCG as the new challenge and new possibilities for municipality development, not to be seen as the burden.

Intermediate integration of sectors and levels is one of the basic conditions for sustainable governance of climate change. Only the integration of climate change in local planning documents and elaboration, adoption and implementation of related decisions, can provide a comprehensive reflection of climate change management in the practice. Providing a clear targeting of planning documents, each target group and every governance level may be able to identify their role in climate change governance.

In order to complete municipal climate change governance cycle development and, subsequently, to be able to observe and monitor climate change adaptation strategies progress, the performance indicators system was developed that provides information to the public and decision makers about both the climate change and the related actions. When developing such indicators system, especially the locally needed information to be provided by the indicator system are important [11]-[13].

Based on the results of our previous studies [8], the indicator system shall be based on the sustainable development governance indicator definition and indicator system development algorithm system of 24 indicators has been structured along all four sustainability dimensions 
[12]. For nine of these indicators the methodology for their calculation has been developed and, by testing them in practice, the calculation has been carried out. Indicators show that the risk of adaptation measures in the Salacgriva municipality so far has been generally successful.

The pro-active participation of all target groups involved in the climate change governance is a key to the successful and mutually supportive and complementary collaboration in practice. MCCG requires a systematic and co-ordinated approach. As the research shows, climate change causes complex and multi-sectoral problems and their management requires a complex and multi-sectoral approach, too.

\subsection{Definition of principal coastal governance scenarios}

The objective of Governance Scenarios development task in the BaltCoast project is to investigate existing practice of the Latvian local municipal coastal governance and identify how it can be improved. Based on theoretical studies and previous and current research outcomes [1], [14], the following basic municipal governance scenarios, principal for Latvia, are identified:

1. Base (BAU - business as usual) governance scenario;

2. Top-down governance scenario;

3. Bottom-up governance scenario;

4. Collaborative governance scenario.

Traditionally municipalities are guided by requirements from the national system, the basis of which is set by the following planning documents: 1) National Sustainable Development Strategy until 2030 that acknowledges the coast of the Baltic Sea as a unique area of national interest, where preservation of nature and cultural heritage should be balanced with the promotion of economic development; 2) Strategy for the Coastal Spatial Development for 2011-2017 that aims at development of the coast as a multi-functional space with appropriate infrastructure serving for development and adaptation to the climate change; and 3) National Long-Term Thematic Plan for the Coastal Area of the Baltic Sea which identifies two priority directions: development of coastal infrastructure and collaborative governance system.

The base governance scenario "Business-as-usual model" (BAU) is a law-driven coastal governance model based on nationally set norms and mechanisms. It operates compulsory planning systems and produces standardized planning documents while ensuring minimum requirements for stake-holders' involvement. The practice, all over the Latvian coastal municipalities and particularly in the Salacgriva municipality, shows that many municipalities have piloted and even introduced innovative for Latvia governance elements, which are complementing compulsory BAU activities. The Salacgriva's municipal practice in this respect is valuable source of information. It has been already mentioned that Municipal Council has approved two essential strategic documents that are unique in the Latvian local context Green Municipality Declaration (2010) and Salacgriva Municipality Climate Change Adaptation Strategy (2011). Moreover, they have established institutional mechanisms and procedures for better stake-holders' involvement into development processes. They have set up Consultative bodies for youth and business involvement into decision-making; institutionalized Village Elders' position as a type of mediator body between central administration and community. Besides, to support small scale village level initiatives they have allocated funding (based on the grant schemes) from the local budget. These all are elements of the "top-down governance model". 
General practice in Latvia shows that interest of small rural community activists into particular coastal management issues there is rather small. The local NGOs often do not recognize importance of the coastal issues, and thus do not address them by their activities. However, there are some exceptions. Few local NGOs implemented projects financed from the EU Leader programme by this bringing tangible results in coastal management. Such activities, though incomplete in their substance, create preconditions for development of the "bottom-up governance model".

All above mentioned scenarios are characterised in the table, which provides characteristics of each of scenarios, its implementation specifics, and outlines deficiencies.

Table 1: Characteristics of the governance models.

\begin{tabular}{|c|c|c|}
\hline Main Characteristics & Results in Latvia & Main Reasons for Failures \\
\hline \multicolumn{3}{|c|}{ Business as usual governance model } \\
\hline $\begin{array}{l}\text { Corresponds to } \\
\text { minimum requirements } \\
\text { defined by the national } \\
\text { legislation for } \\
\text { development planning } \\
\text { process that requests } \\
\text { (mandatory) integration } \\
\text { of coastal issues into } \\
\text { municipal planning } \\
\text { documents: municipal } \\
\text { sustainable development } \\
\text { strategy (for } 25 \text { years), } \\
\text { municipal development } \\
\text { programme ( } 7 \text { years), } \\
\text { and spatial plan ( } 7-12 \\
\text { years). }\end{array}$ & $\begin{array}{l}\text { Partially works for } \\
\text { development } \\
\text { planning/governance } \\
\text { practice of larger coastal } \\
\text { municipalities (cities); but } \\
\text { very limited works for } \\
\text { small (rural) coastal } \\
\text { municipalities. }\end{array}$ & $\begin{array}{l}\text { Municipal administrations that include planning } \\
\text { units have insufficient capacity and low interest } \\
\text { for such integration, thus only formal integration } \\
\text { is performed, if any. } \\
\text { Relevant state administration bodies have no } \\
\text { sufficient capacity to supervise the fulfilment of } \\
\text { this requirement. } \\
\text { The involvement of stakeholders and society in } \\
\text { general in this process is weak. } \\
\text { Small coastal municipalities' specialists do not } \\
\text { have sufficient coastal information and have } \\
\text { limited knowledge on how to perform such } \\
\text { integration in real municipal development } \\
\text { planning/governance practice. }\end{array}$ \\
\hline \multicolumn{3}{|c|}{ Top-down governance model } \\
\hline $\begin{array}{l}\text { The ICM is integrated } \\
\text { within the general } \\
\text { municipal governance } \\
\text { media (as refers content, } \\
\text { process and products); } \\
\text { Municipality takes full } \\
\text { responsibility for coastal } \\
\text { governance, with at least } \\
\text { formal (mandatory } \\
\text { requested by the law) } \\
\text { involvement of local } \\
\text { stakeholders. }\end{array}$ & $\begin{array}{l}\text { Municipalities are not yet } \\
\text { capable nor truly interested } \\
\text { to fully undertake such } \\
\text { comprehensive } \\
\text { responsibility }\end{array}$ & $\begin{array}{l}\text { Even having a number of environmental planning } \\
\text { initiatives and tools in place, there is not enough } \\
\text { local incentive to develop coastal } \\
\text { planning/governance. } \\
\text { Latvian coastal municipalities (excluding large } \\
\text { cities) have limited capacity (financial, human } \\
\text { and institutional resources) to implement this } \\
\text { scenario successfully in practice. } \\
\text { Financing of coastal investments currently is } \\
\text { mainly based on external sources, that are } \\
\text { limited because of: (i) availability of funding in } \\
\text { both sufficient amount and appropriate time } \\
\text { scale; and (ii) thematic restrictions regarding use } \\
\text { of funds (priorities are determined at the national } \\
\text { level). }\end{array}$ \\
\hline \multicolumn{3}{|c|}{ Bottom-up governance model } \\
\hline $\begin{array}{l}\text { To a large extent coastal } \\
\text { governance is } \\
\text { implemented by local } \\
\text { coastal stakeholders in } \\
\text { partnership with } \\
\text { municipal bodies - } \\
\text { social } \\
\text { ownership/involvement } \\
\text { phenomena or ICM } \\
\text { function delegation } \\
\text { approach }\end{array}$ & $\begin{array}{l}\text { Bottom-up stakeholders are } \\
\text { very important actors in } \\
\text { maintaining local coastal } \\
\text { infrastructure; } \\
\text { However, implementation } \\
\text { of coastal governance at } \\
\text { whole municipal scale is } \\
\text { not possible by mainly } \\
\text { using bottom-up elements }\end{array}$ & $\begin{array}{l}\text { Bottom-up practice elements mainly are too local } \\
\text { and focused on particular locality or stake-holder } \\
\text { needs. } \\
\text { Communication along lengthy coastal line and } \\
\text { collaboration between local groups is limited } \\
\text { due to bias interests or lack of collaboration } \\
\text { interest/experience; } \\
\text { Content analysis of local initiatives (EU Leader } \\
\text { programme projects) indicate that projects focus } \\
\text { on activities which solve socio-economic needs } \\
\text { but are not targeted to the coastal issues as such. }\end{array}$ \\
\hline
\end{tabular}


As seen from the table, none of scenarios can be implemented in isolation and bring optimal results for the ICM. On the other hand, each of the scenarios has elements that are essential for effective ICM. Thus, it is obvious to look for the best consolidation of those elements in the new type of collaborative governance scenario (CGS) that shall be implemented to improve governance for ICM. CGS shall meet three principal requirements: (i) shall be based on multi-disciplinary research results, (ii) shall have comprehensive and vigorous stakeholders' involvement component, as well as (iii) useful elements of other governance scenarios that shall be complementary incorporated in the new model.

The analysis of current practice of Latvian coastal municipalities reflects necessity to include a number of tools in CGS

1. contain clearly identifiable science-based quantified numerical information;

2. tools are not separate, but integrative in their nature, succession and unity/complementarity with other coastal governance instruments, application of which might provide significant input into development of the coastal action planning; and

3. synergetic effects of combined application of integrative instruments is powerful.

The CGS built for Salacgriva municipality case is designed based on complementarity of the following governance tools: Coastal Governance Thematic Report; Municipal Coastal Collaborative Monitoring Programme; Municipal Coastal and Development Indicators System; and Coastal Thematic Spatial Planning. Brief justification of this idea is provided further on in the article.

The essence of SAF is to develop tool which helps to mediate interface between the science and stakeholders (who at the same time might be considered as decision makers). The classical SAF approach is to use and demonstrate for that purpose ecological-economic scenario results. The analysis of Latvian research team within BaltCoast project has shown that in Municipal Governance case that was used for the Salacgriva municipality case study helpful mediation tool or interface might be a Coastal Governance Thematic Report, based on and approved as a result of public participation process. The system elements and links of the system model, developed within the SAF application process, serve as a background for formulation content of the Thematic Report. This Report has not only governance part in it, but all parts of SES, which means it includes nature, economic and social data and discusses them from the governance aspects. In the next step of the BaltCoast project to be implemented in 2017, the Report will be elaborated in detail. Following, demonstration of the existing coastal governance status, trends and conclusions identified by the Report to the stakeholders and decision makers and consultation/discussing it might effectively open space for collaborative decisions.

The Thematic Report corresponds to the same principal requirements, which are fulfilled by the classical SAF scenarios: (i) it considers the coast as the socio ecological system; (ii) is science data based and contains comprehensive quantitative information, (iii) ensures cross-linkage evaluation of coastal system data;(iv) is easily understandable for local stakeholders/decision makers (if written in user-friendly/ perceptible language); (v) it is based on and reflect the values of local society, (vi) discussion on Report content's will help to recognize undesirable situations (factors and values whose development shows negative for society trend) which shall be improved by governance decision/activities.

Municipal Coastal Collaborative Monitoring Programme is a comprehensive system that has to be designed in a way to motivate and involve in its implementation various stakeholders (including those who have demonstrated already interest in similar processes, like local schools, village NGO's, interest groups or elderly people associations etc.) in 
collaboration with the municipality's service organizations, and shall serve for both municipal coastal and development governance needs, and public involvement [1], [15].

Municipal Coastal and Development Indicators System contains both "top-down" and "bottom-up" indicators. The later are based on citizens' science approach and it means, that citizens groups will be involved in development and evaluation of these indicators, and data collection. The evaluation of the summarised trend, indicated by the whole system of indicators will serve as the effective pressure/ tool on decision makers.

Coastal Thematic Spatial Planning means realization of disciplinary/thematic approach. In the present situation of Latvia this is a voluntary decision taken by the municipality on development of such specialized planning document. Such plan accordingly will be important part of the municipal spatial plan (this is stipulated by the law on development planning that outlines planning documents hierarchy), and it will help to better zoning of the coastal territory based on its development needs and opportunities.

Governance tools shall be integrated within municipal governance/ development planning system both in compulsory planning documents (Sustainable Development Strategy, Development Programme, Spatial Planning document, and supplementary to it Financial Action Programme) and in other type of (voluntary) planning documents. The integrative development and application of all noted above, as it:

1. Provides data for municipal coastal and development governance needs which municipality administration and subordinated institutions cannot obtain by themselves due to limited resources and insufficient capacity;

2. Strengthens cooperation between citizen groups themselves, between citizens groups and municipality, and creates faithfulness among involved parties;

3. By demonstrating weak points and adverse development trends motivates to change the situation and get involved in solution building;

4. Is appropriate tool for starting coastal governance improvements as improvements might be started at different scale: small or large (ex., local or national).

\subsection{Coastal Science-Policy-Practice Interface Development}

The essential component of the research objective within the BaltCoast project is to demonstrate the transition process from separate isolated (disciplinary) research activities to unified comprehensive multi-disciplinary coastal research by demonstrating the benefits of application of the multi-disciplinary coastal research approach to development and implementation of full coastal governance cycle (from problem identification/analysis to measures/actions, monitoring and corrective actions/revision).

Multidisciplinary coastal research system requires adequate combination of both academic science and citizens' science elements [16]-[18]. Such combination will be demonstrated within Salacgriva case study. Citizens science research done in the context of coastal issue and particularly in the Salacgriva municipality coastal territory includes activities covering such issues as: marine and beach litter evaluation (quantitative inventory); photo documentation of situation in the coastal territory; and interrogation of the coastal inhabitants/visitor.

Studies reveal that decision-makers have insufficient science-based information and understanding of the coastal specific. Scientific information about the physical state of the coast from the monitoring or other observations and scientific scources is often complex, natural science orientated and difficult to be used for decisions-making [15]. The challenge for us as researchers is to find way how to provide interface between science and policy, so to translate, transfer and integrate scientific knowledge into decision making and 
implementation practice [14]. It has been concluded from earlier studies that it is necessary to create science-based and at the same time easily applicable and interpretable municipal coastal monitoring and coastal indicators system [14].

Proposed by the researchers, the system is based on nature-social science factors and their interaction, and includes citizen science components [15]. Coastal communication is seen here within two basic complementary frameworks: (i) as science-policy interface communication and also as (ii) stakeholders' communication. It is necessary to design an integrated coastal science communication content and products and prepare authorities and stakeholders for participation in the communication process which all in all shall be integrated into the coastal governance process.

The most important socio-natural processes and impacts parameters based scheme is the core of to be designed and applied municipal coastal monitoring system, finding a key coastal indicators and improvement of ICM models and scenarios. The introduction of municipal coastal monitoring program, based on various types of applied measurements done by local employees and stakeholders/citizens groups, and being suitable for unambiguously interpretation of coastal state $\&$ conditions are those real instrument considered by authors that could be applied by coastal municipalities and used in practice for coastal policy development and implementation thus having municipal practice based way of ensuring the interface between coastal science and policy. Municipal monitoring program offers specifically minimal-optimal research amount, quantitatively describing the state of a coastal system. Important, the municipal applied monitoring should include both nature and socioeconomic monitoring and particular programs of municipal monitoring should be adapted for different CAC.

Elaboration of an indicator system embodies one of the most effective forms of public participation as indicators offer new information for the public and elaboration of indicators, data gathering and calculation involves somebody possessing important information. It has to be noted that indicator initiative processes are not less significant than the result - the elaborated indicators. In order to manage to inquire and acquire not only physical parameters of shoreline, but also the real picture at the social part of shoreline and that of the whole local coastal municipality there is necessary to approach all main stakeholder groups: municipal council (politicians, managers/ planners, subordinated); households/inhabitants, corporative (business) sector, and to be in close collaboration with state administrative institutions, and all intermediaries as mediators (media, NGO, educators, and science people).

The proposed science-policy interface might serve also as the effective mediator tool to serve predictable problems related to ICM implementation. Some of those problems are: contradictions of municipal development planning interests with restrictions stated by national level; antagonism of opinions from different stakeholders; risk for increased focus on coastal areas; lack of unbiased information about processes in coastal areas; insufficient understanding about ICM on municipal level.

\section{CONCLUSIONS}

The conceptual definition of the Social-Ecological System is based on the sustainable development approach, which proposes that coastal systems are based on interconnected elements of the complex resources system consisting of natural, cultural, socio-economic, and, especially we would be adding also governance resources (systems). Thus, the concept of four systems served as a basis for the model development.

The SAF application is an innovative task, especially for the governance systems. Based on the general approach of the SAF, the authors applied in the case analysis a specifically designed step-wise approach seeking to develop the coastal resource governance system. The 
problem analysis performed by the authors demonstrates application of the problem analysis methodology in a situation which is typical for Latvian rural coastal territories - there are not severely dominating problems in the majority of these territories, but there is relatively high amount of small problems which with mutual synergy influence cause a multiplier effect. Finally, the authors arrived at the generic problems, the solutions to which should be found focusing on the coastal governance system itself.

In the Latvian context, it appeared to be essential to find ways how to organise coastal governance (the governance process, content and structure) in the coastal rural territories, which are characterised by a small number of residents and low population density, limited administrative capacity, but having a long coastline, compare to coastal towns. It principally affects the way how a territory and its resources shall be managed and governed. In most of the rural coastal territories in Latvia local coastal governance is comparatively underdeveloped and limited, what results in unsustainable use of the coastal resources, thus preventing local development and causing coastal degradation which remains a threat to sustainability of the resources and coastal local communities' resilience.

However, limited capacity of the coastal municipalities' administrations (in terms of human resources, governance instruments and economic options) considerably affects the traditional "top-down" approach of the municipal governance realisation as well as its efficiency. The solution should be found in further development of the "bottom-up" governance models by strengthening the interaction of the "top-down" and "bottom-up" governance, i.e. collaboration in the local governance development. The needs of the local coastal citizens interact also with the needs of visitors and the wider society. Actually, it is necessary to find a balance between these needs. System Thinking and the application of System Approach Framework (SAF), including participatory decision-making process, are tools that allow passing sequentially through various stages of the system analysis, thus arriving at the common denominator in the coast and coastal resources governance acceptable for all involved stakeholders.

ICM requested coastal nature-social science results interaction needed is to be transformed into local level science-policy-practice chain governance, and that could be done as particular interface process and content development, being based on structural design of to be elaborated/tested local municipal coastal monitoring system (incl. citizen science approach) as part of local municipal development governance, what also could be seen as important developments towards coastal municipal resilience.

In overall, the application of SAF methodology and adaptation of it to the specific coastal governance research case in Latvian pilot study site at the Salacgriva municipality allowed:

1. novel application of the SAF methodology;

2. building of a new collaborative governance model and design its essential tools;

3 . to create an interface between science, policy (decision making) and practice (society);

4. to conceptualize coastal monitoring programme as an essential tool for collaborative governance that is aimed at improved ICM and is based on local ownership and active public engagement.

Despite all international long-term efforts, ICM approach implementation still has been not fully understood and implemented not only in Latvia, especially, taking into account local level specifics. This Salacgriva case study also confirm our previous ICM studies, including in the BaltCoast project, recognizing, that general ICM problems solving still do require basic pre-conditions, generic and innovative ones, e.g. initially involving cross-disciplinary trained and working project/problem team, designing coastal collaboration process for all main 
stakeholder's interests' formulation and interaction process, creating communication media for initiatives and complementary applying of top-down and bottom-up approaches.

\section{ACKNOWLEDGEMENT}

This paper has been prepared with the financial support of the BONUS programme project "A Systems Approach Framework for Coastal Research and Management in the Baltic"(BaltCoast), realized at the University of Latvia, and reflects the research activities and conclusions done within this project, which were initially based on a coastal sciencepolicy interface model and coastal governance general approaches/scenarios [14], elaborated and designed while our project team work for National Research Program SUSTINNO (2014-2017).

\section{REFERENCES}

[1] Lagzdina, E., Kudrenickis, I., Ernsteins, R. \& Kaulins, J., Coastal Sustainable development studies in Latvia: Integrated local social-ecological systems governance. Journal of Regional formation and development studies, 21(1), pp. 83-97, 2017.

[2] Ostrom, E., A General Framework for Analysing Sustainability of Social-Ecological Systems. Science, (325), pp. 419-422, 2009.

[3] Hopkins, T.S., Bailly, D. \& Stottrup, J.G., A Systems Approach Framework for Coastal Zones. Ecology and society, 16(4), p. 25, 2011.

[4] Karpouzoglou, T., Dewulf, A. \& Clark, J., Advancing Adaptive Governance of SocialEcological Systems through Theoretical Multiplicity. Environmental Science \& Policy, 57, pp. 1-9, (2016).

[5] Hopkins, S.T., Bailly, D., Elmgren, R., Glegg, G., Sandberg, A. \& Støttrup, J.G., A Systems Approach Framework for the Transition to Sustainable Development: Potential Value Based on Coastal Experiments. Ecology and Society, 17(3), p. 39, 2012.

[6] Strottrup, J.G., Dinesen, G.E., Holder, J., Gillgren, C. \& Schernewski, G., Re-visiting ICM theory and practice: Lessons learned from the Baltic Sea Region. Ocean \& Coastal Management, 139, pp. 64-76, 2017.

[7] Ernsteins, R., Lontone-Ievina, A., Lagzdina, E., Oseniece, K. \& Kaulins, J., Integrated coastal management practice case studies: deficiency of collaboration communication and socio-ecological system approaches. Proceedings of: 2017 International Conference "Economic Science for Rural Development, Latvian University of Agriculture, Jelgava, pp. 63-71, 2017.

[8] Kaulins, J., Ernsteins, R. \& Kudrenickis, I., Sustainable development indicators for integrated coastal management: Definition area and spatial properties. 8th International Conference on Ecosystems and Sustainable Development, Ecosystem and Sustainable Development VIII. WIT Transaction on Ecology and the Environment, 144, WIT Press, pp. 299-311, 2011.

[9] Ernšteins, R., Sustainable coastal development in Latvia: Collaboration communication and governance imperative. Sustainable Coastal Development: Collaboration Governance (Ernšteins R., Jūrmalietis R., eds.), University of Latvia Academic Publishing, Riga, Latvia, pp. 159-178, 2008.

[10] Kudreņickis, I., Ernšteins, R., Lontone, A., Kauliņš, J., Zvirbule, L., Strazdiņš, J. et al., Municipal Climate Change Adaptation Governance in Latvia: Approaching CrossSectorial and Multi-Intrumental Understanding. Journal of Regional Formation and Development Studies, 14(3), Klaipeda, pp. 40-52, 2014. ISSN 2029-9370, DOI: http://dx.doi.org/10.15181/rfds.v14i3.862. 
[11] Moreno, S. \& Fidelis, T., Local sustainability indicators in Portugal: assessing implementation and use in governance contexts. Journal of Cleaner Production, 86, pp. 289-300, 2015.

[12] Rydin, Y., Holman, N. \& Wolff, E., Local Sustainability Indicators. Local Environment, 6, pp. 581-589, 2003.

[13] Valtenbergs, V., González, A. \& Piziks, R., Selecting indicators for sustainable development of small towns: the case of Valmiera municipality. Procedia Computer Science, 26, pp. 21-32, 2013.

[14] Kudrenickis, I., Ernsteins, R. \& Kaulins, J., Sustainable Coastal Science-PolicyPractice Interface Development: Municipal Coastal Governance Indicator System. Journal of Environmental Science, 1, pp. 255-264, 2016.

[15] Cepurītis, E., Ulme, J. \& Graudina-Bombiza, S., Development of Beach litter monitoring on the Latvian coastline: the citizen science perspective. Journal of Regional formation and development studies, 21(1), pp. 19-33, 2017.

[16] Mette, A., Bridging the Gap between Science and Society. P. Tett, A. Sandberf, A. Mette, eds. Sustainable Coastal Zone Systems, Dunedin Academic Press, Edinburgh, UK, pp. 103-135, 2011.

[17] Conrad, C.C. \& Hilchey, K.G., A Review of Citizen Science and Community-Based Environmental Monitoring: Issues and Opportunities. Environmental Monitoring Assessment, (176), pp. 273-291, 2011.

[18] Mascarenhas, A., Nunes, L. \& Ramos, T.B., Exploring the self-assessment of sustainability indicators by different stakeholders. Ecological Indicators, 39, pp. 75-83, 2014. 